\title{
Aerodynamic Analysis of Blended Wing Body - Unmanned Aerial Vehicle (BWB-UAV) Equipped with Horizontal Stabilizers
}

\author{
Nornashiha Mohd Saad ${ }^{1}$, Wirachman Wisnoe ${ }^{1}$, Rizal Effendy Mohd. Nasir ${ }^{1}$, Zurriati Mohd Ali ${ }^{2}$, and Ehan Sabah Shukri \\ Askari $^{3}$ \\ ${ }^{1}$ Flight Technology and Test Centre (FTTC), Faculty of Mechanical Engineering, Universiti Teknologi MARA (UiTM), 40450 Shah \\ Alam, Selangor DE, Malaysia \\ ${ }^{2}$ Faculty of Mechanical Engineering, Universiti Teknologi MARA (UiTM), Johor, Malaysia \\ ${ }^{3}$ Engineering Technical College-Baghdad, Middle Technical University (MTU), Baghdad, Iraq
}

\begin{abstract}
This paper presents an aerodynamic characteristic study in longitudinal direction of UiTM Blended Wing Body-Unmanned Aerial Vehicle Prototype (BWB-UAV Prototype) equipped with horizontal stabilizers. Flight tests have been conducted and as the result, BWB experienced overturning condition at certain angle of attack. Horizontal stabilizer was added at different location and size to overcome the issue during the flight test. Therefore, Computational Fluid Dynamics (CFD) analysis is performed at different configuration of horizontal stabilizer using Spalart - Allmaras as a turbulence model. CFD simulation of the aircraft is conducted at Mach number 0.06 or $\mathrm{v}=20 \mathrm{~m} / \mathrm{s}$ at various angle of attack, $\alpha$. The data of lift coefficient $\left(C_{L}\right)$, drag coefficient $\left(C_{D}\right)$, and pitching moment coefficient $\left(C_{M}\right)$ is obtained from the simulations. The data is represented in curves against angle of attack to measure the performance of BWB prototype with horizontal stabilizer. From the simulation, configuration with far distance and large horizontal stabilizer gives steeper negative pitching moment slope indicating better static stability of the aircraft.
\end{abstract}

\section{Introduction}

Blended Wing Body (BWB) aircraft is tailless design that combined wing and fuselage $[1,2]$. Compared to conventional aircraft, BWB is usually better in terms of aerodynamic performance, lower fuel burn and lower noise emission [3]. Reduction of maximum takeoff weight (MTOW) by $15 \%$ and reduction of fuel burn per seat by $28 \%$ lower the operating cost of BWB [4]. BWB increases range and payload capacity with $27 \%$ reduction in fuel burn per seat [5]. According to $\mathrm{M}$. Nasir et al., BWB concept can save up to $30 \%$ of fuel consumption by improving the lift-to-drag ratio [6]. However, there are some issues in BWB related to aerodynamic, structures and control [2].

Aerodynamic characteristics of an aircraft can be obtained through simulations and experiments. Panagiotou et al. applied Reynolds-Averaged NavierStokes (RANS) equations solver with the SpalartAllmaras turbulence model to obtain the aerodynamic characteristics on three different configurations of BWB design: 1. $\mathrm{V}$ tail, 2. canards with a set of winglet and rudder, and 3. winglets with elevons. The analysis was conducted at airspeed of $39 \mathrm{~m} / \mathrm{s}$. From the simulation, configuration 2 gave highest lift coefficient $\left(\mathrm{C}_{\mathrm{LMax}}\right)$ at an angle of attack of $-12^{\circ}$ and configuration 3 produced higher aerodynamic efficiency and lower zero-Lift Drag coefficient [2]. CFD simulation also has been done on
BWB by Dehpanah and Nejat using Spalart Allmaras turbulence model with $\mathrm{Re}=200,000$ at various angles of attack from $-16^{\circ}$ to $25^{\circ}$. The curve of lift-to-drag ratio against lift coefficient shows its maximum value of 8.5 at 0.175 lift coefficient. High lift coefficient and low drag coefficient is needed to reduce fuel consumption and to increase the range [7]. Wind tunnel experiments have been conducted by Shim and Park on BWB-UCAV model at free stream velocity of $50 \mathrm{~m} / \mathrm{s}$. Internal balance was used to measure different forces and moment coefficients. Maximum lift coefficient obtained is 0.868 at $20^{\circ}$ angle of attack and the zero lift angle is produced at about $0.75^{\circ}$ angle of attack [8].

Since September 2005, UiTM has started a research on BWB-UAV [9]. There were several studies that had been carried out on BWB using CFD, wind tunnel, and finite element method [10]. Recently, wind tunnel experiment has been done in Baseline- $\mathrm{V}$ at Mach number 0.05 . When the angle of attack ranges from $-5^{\circ}$ to $-2^{\circ}$, zero coefficient of lift is recorded and highest $\mathrm{L} / \mathrm{D}$ ratio is 32 [11]. Wisnoe et al. performed CFD analysis on Baseline-II equipped with one central vertical rudder. The meshing produced $8 \times 10^{5}$ cells and the air speed was set at $35 \mathrm{~m} / \mathrm{s}$. The vertical rudder produced higher side force than slip drag flaps ten times in magnitude when compared with other study [12].

In August 2014, Universiti Teknologi Mara (UiTM) Malaysia has been granted a research project under 
Prototype Research Grant Scheme (PRGS) from Malaysian Ministry of Higher Education (MOHE) to fabricate a prototype of Blended Wing Body-Unmanned Aerial Vehicle (BWB-UAV) for aerial surveillance [13]. Fig. 1 is the BWB Prototype at different views. Wind tunnel experiments have been done on $1 / 4$ scaled half model of BWB aircraft at various angles of attack. The results show the maximum lift coefficient of around 0.65 at $28^{\circ}$ angle of attack, the minimum drag coefficient is below 0.03 at zero angle of attack and the maximum liftto-drag ratio is 20 at $3^{\circ}$ angle of attack [13]. CFD simulation also was conducted on various angles of attack and various angles of elevator deflections of the canard. At angle of attack $30^{\circ}$ and canard deflection $0^{\circ}$, lift coefficient maximum is 1.0505 [14].

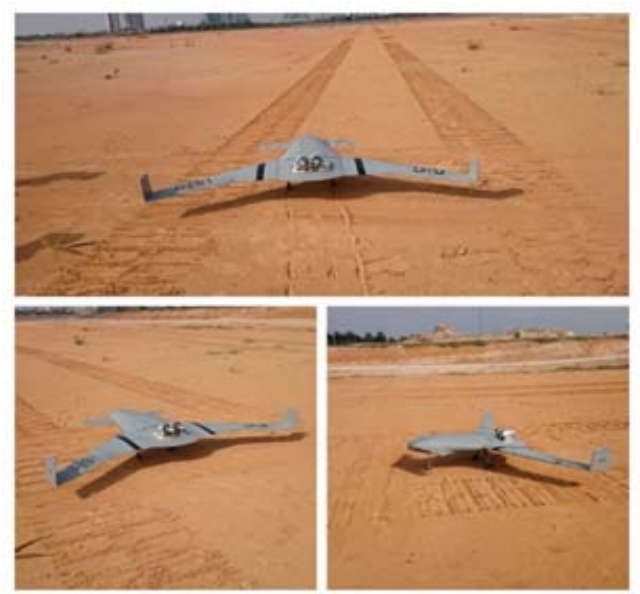

Fig. 1. UiTM BWB-UAV Prototype.

During the flight test of BWB Prototype, it was observed that the prototype has some issues in the longitudinal direction. After certain angles of attack, the BWB experienced overturning after a few seconds airborne. The addition of horizontal stabilizer was done to overcome these issues. Fig. 2 shows the BWB Prototype fitted with tail boom and horizontal stabilizer. This paper aims to analyse the aerodynamic characteristics of BWB-UAV equipped with horizontal stabilizer at different locations and sizes. Lift, drag, and pitching moment coefficients will be presented.

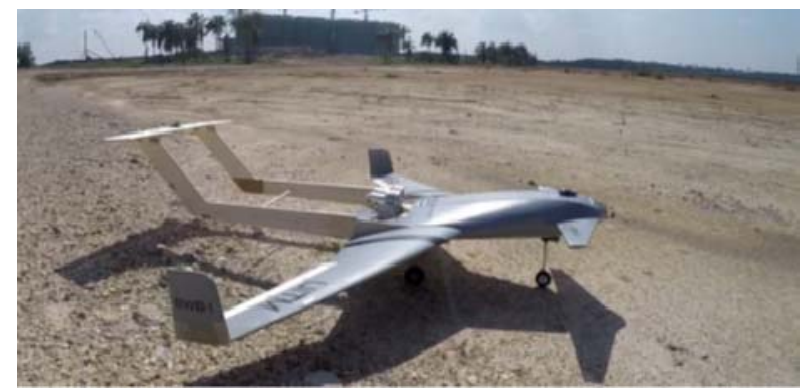

Fig. 2. UiTM BWB-UAV Prototype with horizontal stabilizer.

\section{CFD setup}

Table 1 shows the three configurations of horizontal stabilizer on BWB on which the simulation was performed.

Table 1. Table of three configuration of horizontal stabilizer.

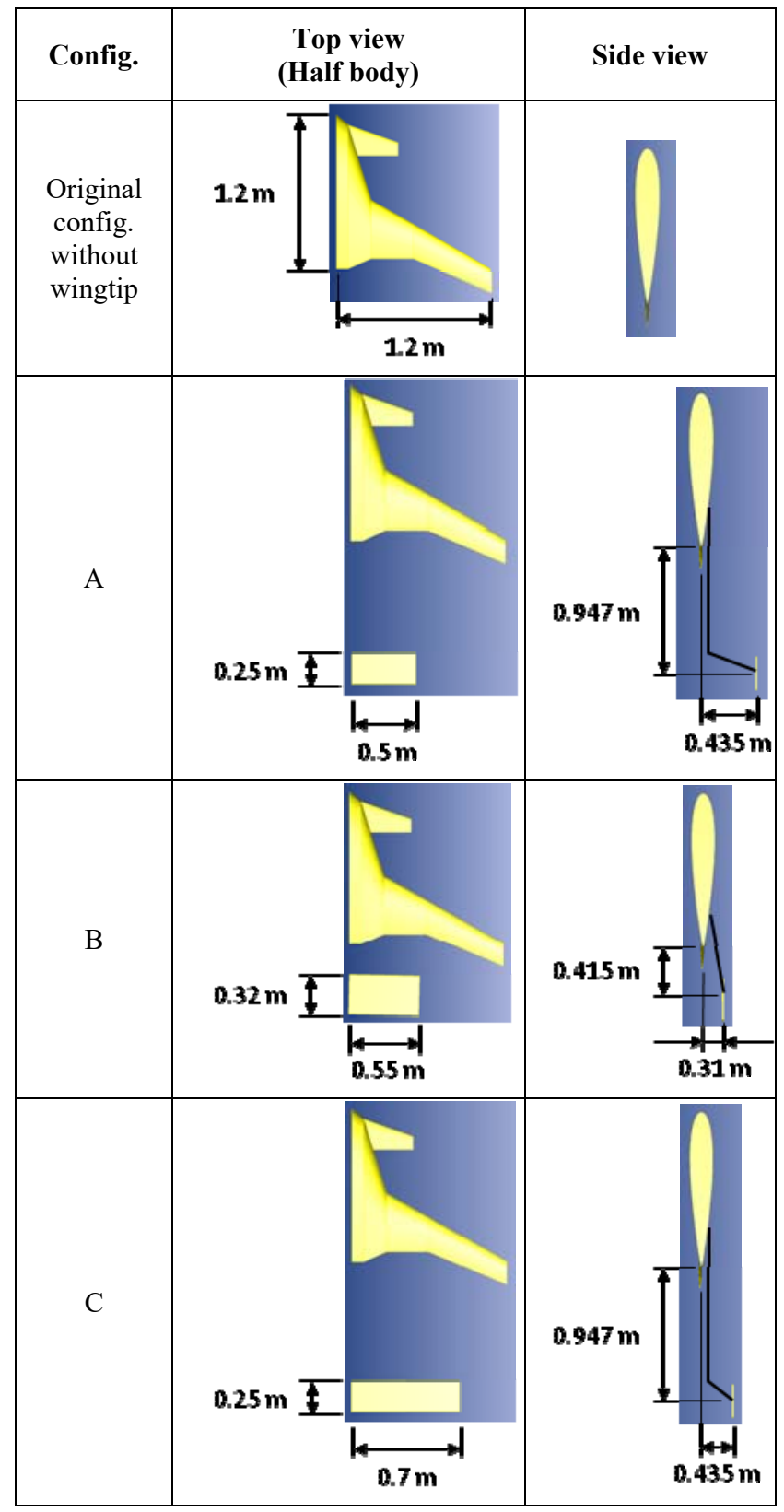

The CFD simulation was done in NUMECA FineOpen v3.1-1 software. The number of cells for configuration A, B and C are 770,000, 690,000 and $1,480,000$ respectively. In processing stage, simulation was run at velocity $20 \mathrm{~m} / \mathrm{s}$ with corresponding Reynolds number around $5.31 \times 10^{5}$. The simulation was performed under steady state configuration using air as perfect gas at room temperature $(300 \mathrm{~K})$ and at 1 atm. SpalartAllmaras was used as a turbulence model for this simulation. The simulation was performed at angle of attack of $-10^{\circ}$ up to $34^{\circ}$. The tail boom and wingtip were removed to simplify the simulation. Table 2 shows the parameter used in the simulation. 
The results obtained were plotted to obtain the curves of $C_{L}, C_{D}$ and $C_{M}$ at various angles of attack

Table 2. Simulation parameters.

\begin{tabular}{|l|l|}
\hline \multicolumn{1}{|c|}{ Parameter } & \multicolumn{1}{c|}{ Value } \\
\hline Reference velocity & $20 \mathrm{~m} / \mathrm{s}$ \\
\hline Reynold number & $5.31 \times 10^{5}$ \\
\hline Type of fluid & Air (perfect gas) \\
\hline Turbulence model & Spalart-Allmaras \\
\hline Reference length & $0.49569 \mathrm{~m}$ \\
\hline Reference area & $0.59609 \mathrm{~m}^{2}$ \\
\hline Angles of attack & $-10^{\circ}$ to $34^{\circ}$ \\
\hline
\end{tabular}

\section{Validation}

Comparison of CFD results with the results from wind tunnel tests is executed for validation. For this purpose the BWB Prototype original configuration (with wing tips and canard) was used both in the CFD and wind tunnel tests with $1 / 4$ of the real size model. The model's reference length is $0.291 \mathrm{~m}$ and its reference area is $0.035054 \mathrm{~m}^{2}$. The airspeed was set at $20 \mathrm{~m} / \mathrm{s}$. The results are presented in Fig. 3 and Fig. 4.

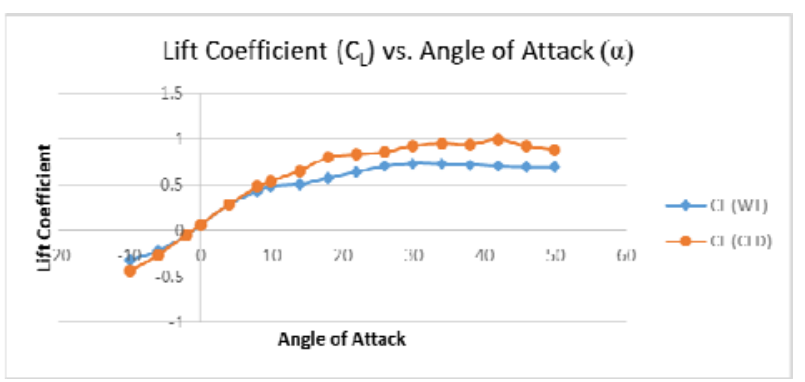

Fig. 3. Lift Coefficient $\left(C_{L}\right)$ vs angle of attack $(\alpha)$ of BWB Prototype model.

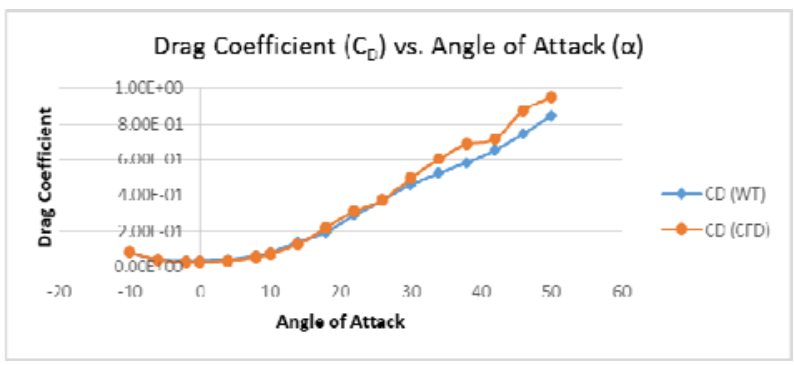

Fig. 4. Drag Coefficient $\left(C_{D}\right)$ vs angle of attack $(\alpha)$ of BWB Prototype model.

From these figures, it is observed that both curves from CFD and wind tunnel have similar trends with only slight deviation at higher angles of attack (above $10^{\circ}$ for $\mathrm{C}_{\mathrm{L}}$ and above $30^{\circ}$ for $\mathrm{C}_{\mathrm{D}}$ ). The $\mathrm{C}_{\mathrm{L}}$ curve from wind tunnel shows a slight deflection at $\alpha=12^{\circ}$ (Fig. 3) which corresponds to the occurrence of stall at the outer wing (visualized using thread tufts visualization) [13]. The graph representing CFD result does not detect any partial stall at that angle of attack. This might be due to the setting of parameters for the CFD simulation including the selection of turbulence model.

\section{Results and discussion}

\subsection{Lift coefficient analysis}

Fig. 5 below shows a graph of lift coefficient versus angle of attack. All configurations were observed to have the same trend where $\mathrm{C}_{\mathrm{L}}$ increases as the angle of attack increases. When $C_{L}$ is at maximum, the curves start to decrease. After $\alpha=10^{\circ}$, the configuration $C$ shows higher values compared to other configurations. The original configuration shows a deflection around this angle, which is due to partial stall on the outer wing [13]. Configuration A also shows deflection around this angle. The effect of partial stall on the outer wing to the lift coefficient is insignificant in configurations $\mathrm{B}$ and $\mathrm{C}$. This may be due to the fact that horizontal stabilizers used in $\mathrm{B}$ and $\mathrm{C}$ are larger. Configuration $\mathrm{C}$ shows highest $C_{L}$ at $\alpha=34^{\circ}$ with $C_{L}$ value of 1.551 .

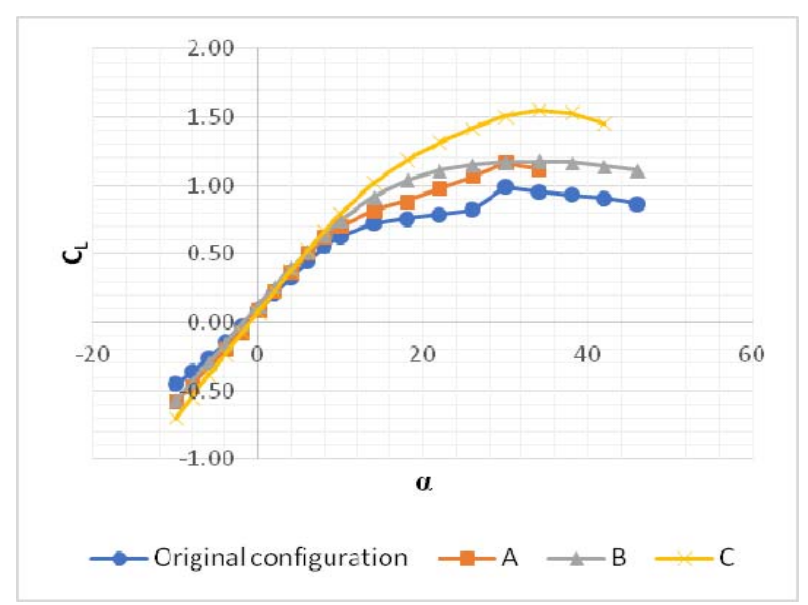

Fig. 5. Lift coefficient $\left(C_{L}\right)$ vs angle of attack $(\alpha)$.

\subsection{Drag coefficient analysis}

Fig. 6 shows the curves of drag coefficient against angle of attack for various configurations. The curves have the same trends for all configuration with small differences among the curves from $\alpha=-10^{\circ}$ to $\alpha=6$. At low angles of attack, the airflow is still attached to the body and wing. The value of $C_{D}$ at zero angle of attack is about 0.03 . Above $4^{\circ}, C_{D}$ increases as angle of attack increases. Configuration $C$ has the highest drag value of $C_{D}=1.22$ when $\alpha=40^{\circ}$. This is because it has the largest contact area compared to other conditions. Original configuration has the least drag coefficient following by Configuration $\mathrm{B}$ and Configuration $\mathrm{A}$. A deflection occurs at $\alpha=26^{\circ}$ for original configuration and $\alpha=34^{\circ}$ for Configuration A. 


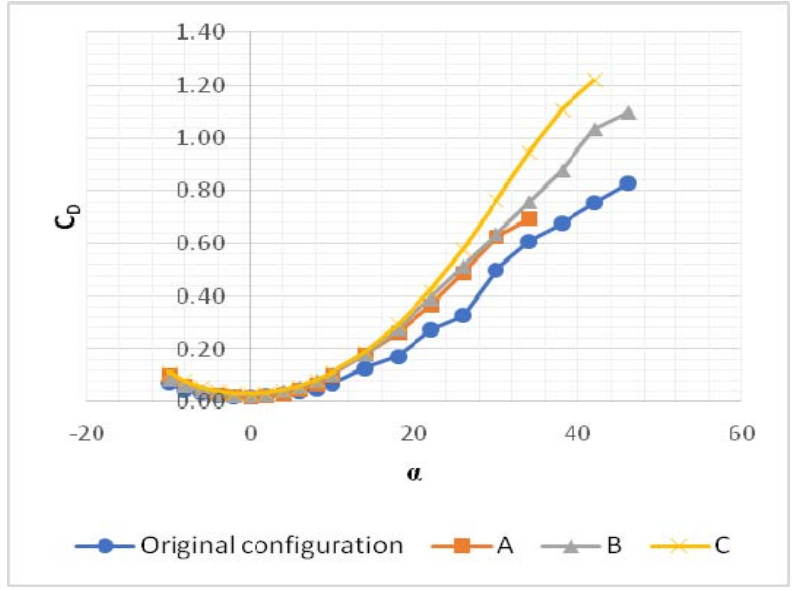

Fig. 6. Drag coefficient $\left(C_{D}\right)$ vs. angle of attack $(\alpha)$.

\subsection{Pitching moment coefficient analysis}

Graph of pitching moment coefficient versus angle of attack is shown in the Fig. 7. The measurement of the pitching moment is taken at $600 \mathrm{~mm}$ from the nose of BWB Prototype, which is approximately at the midpoint of the length of BWB. It is seen that moment coefficient decreases for all conditions as the angle of attack increases. At $\alpha=0^{\circ}$ all curves show negative pitching moment which means the aircraft has tendency to nose down at zero-degree angle of attack. A positive slope is detected (on original configuration) at $\alpha=30^{\circ}$ which corresponds to the maximum of lift coefficient. When positive slope is detected, there is a tendency for the aircraft to nose up. Deflection of positive slope also occurs on Configuration $\mathrm{A}$ but it is not obvious at $\alpha=34^{\circ}$ also correspond to maximum lift coefficient. Between $\alpha=14^{\circ}$ and $\alpha=18^{\circ}$ of configuration $\mathrm{A}$ and Configuration $\mathrm{B}$, there are almost zero slope which means that the moment is almost independent of $\alpha$. The CFD result shows Configuration $\mathrm{C}$ has highest negative pitching moment with a steep slope compared to others condition.

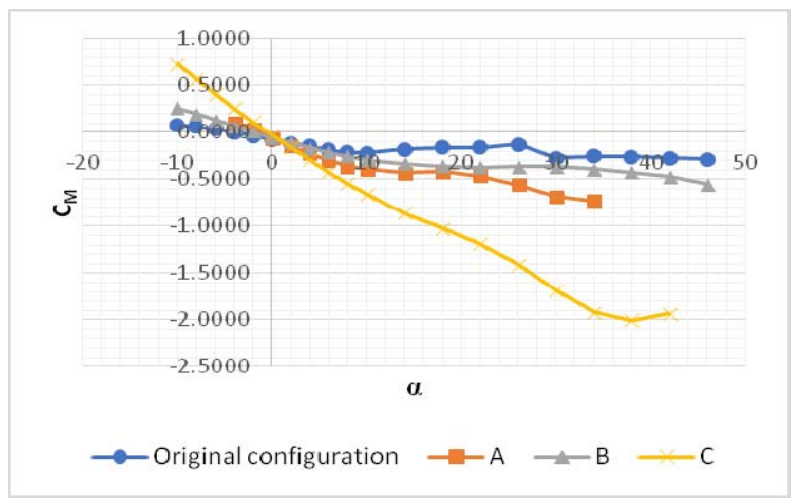

Fig. 7. Pitching moment coefficient $\left(\mathrm{C}_{\mathrm{M}}\right)$ vs. angle of attack $(\alpha)$.

\subsection{Drag polar analysis}

The drag polar $\left(\mathrm{C}_{\mathrm{L}}\right.$ versus $\left.\mathrm{C}_{\mathrm{D}}\right)$ curves was plotted in Fig. 8 for all conditions. The value of $C_{D}$ at zero lift $\left(C_{D 0}\right)$ is obtained approximately equal to 0.03 . This is the minimum drag coefficient at zero lift. The curves' patterns are all the same where Configuration $\mathrm{C}$ shows higher $\mathrm{C}_{\mathrm{L}}$ at higher $\mathrm{C}_{\mathrm{D}}$.

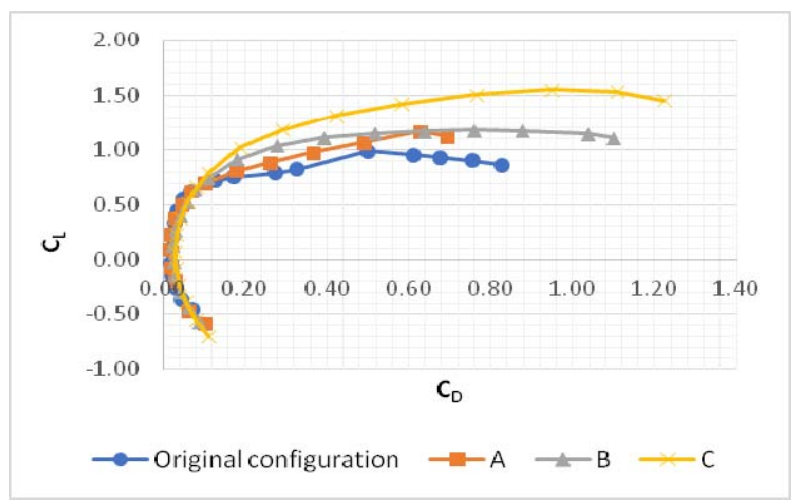

Fig. 8. Lift Coefficient $\left(C_{L}\right)$ vs. Drag Coefficient $\left(C_{D}\right)$.

\subsection{Lift-to-drag ratio analysis}

The curves of $\mathrm{L} / \mathrm{D}$ versus angle of attack was plotted in Fig. 9. Here, the curves almost coincide for $\alpha$ below $2^{\circ}$. For all conditions, L/D increases after $\alpha=-6^{\circ}$ until it reaches its maximum peak and then gradually decreases. The original configuration and Configuration $\mathrm{A}$ both have high peak lift-to-drag ratio around 13 at $\alpha=6^{\circ}$ and $\alpha=4^{\circ}$ respectively. This angle of attack indicates the optimum flight configuration for the aircraft. Configuration $\mathrm{C}$ has the lowest peak in the curve.

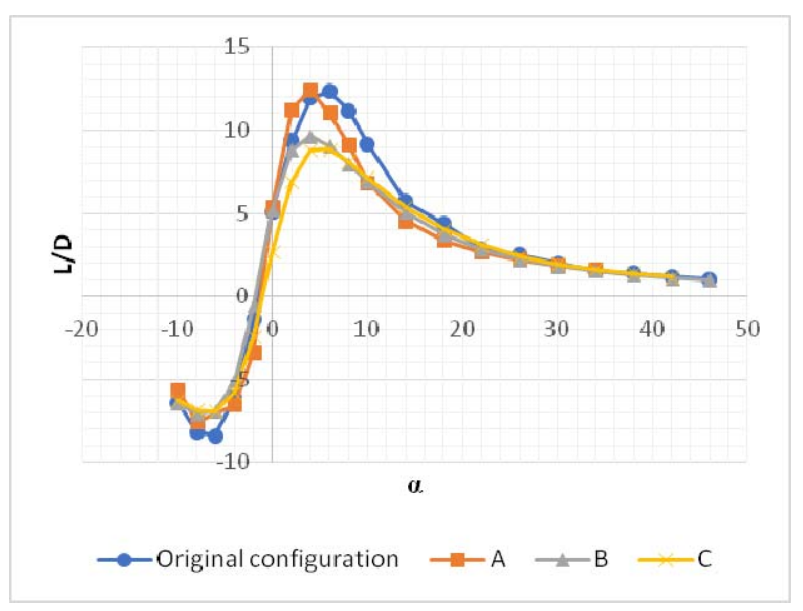

Fig. 9. Lift-to-drag ratio (L/D) vs. angle of attack $(\alpha)$.

\section{Conclusion}

In this paper, the aerodynamic characteristics of UiTM BWB-UAV Prototype have been presented in terms of lift, drag and pitching moment coefficients.

The use of horizontal stabilizer reduces the effect of partial stall on the outer wing above $10^{\circ}$ of angle of attack. The original configuration and Configuration A produce highest lift-to-drag ratio of 12 at $\alpha=6^{\circ}$ and $\alpha=$ $4^{\circ}$ respectively. Configuration $\mathrm{C}$ has the steepest negative pitching moment slope compared to all configurations. It gives a strong moment to nose down 
when the angle of attack increases in the positive side. It increases the static stability during flight.

The authors would like to thank the Faculty of Mechanical Engineering, Universiti Teknologi MARA (UiTM) Malaysia for providing assistance and support for this research.

\section{References}

[1] N. Qin, A. Vavalle, A. Le Moigne, M. Laban, K. Hackett, and P. Weinerfelt, "Aerodynamic Considerations of Blended Wing Body Aircraft", Progress in Aerospace Sciences, 40 (6), 321-343 (2004)

[2] P. Panagiotou, S. Fotiadis-Karras, and K. Yakinthos, "Conceptual Design of a Blended Wing Body MALE UAV", Aerospace Science and Technology, 73, 32-47 (2018)

[3] P. Li, B. Zhang, Y. Chen, C. Yuan, and Y. Lin, "Aerodynamic Design Methodology for Blended Wing Body Transport", Chinese Journal of Aeronautics, 25 (4), 508-516 (2012)

[4] S. Ammar, C. Legros, and J.-Y. Trépanier, "Conceptual Design, Performance and Stability Analysis of a 200 Passengers Blended Wing Body Aircraft", Aerospace Science and Technology, 71, 325-336 (2017)

[5] P. Okonkwo and H. Smith, "Review of Evolving Trends in Blended Wing Body Aircraft Design", Progress in Aerospace Sciences, 82, 1-23 (2016)

[6] R. E. M. Nasir, W. Kuntjoro, and W. Wisnoe, "Aerodynamic, Stability and Flying Quality Evaluation on a Small Blended Wing-body Aircraft with Canard Foreplanes", Procedia Technology, 15, 783-791 (2014)

[7] P. Dehpanah and A. Nejat, "The Aerodynamic Design Evaluation of a Blended-Wing-Body Configuration", Aerospace Science and Technology, 43, 96-110 (2015)
[8] H. J. Shim and S. O. Park, "Low-Speed WindTunnel Test Results of a BWB-UCAV Model", Procedia Engineering, 67, 50-58 (2013)

[9] R. E. M. Nasir, F. Mohamed, R. Ramly, A. M. I. Mamat, W. Wisnoe, and W. Kuntjoro, "Flight Performance of Various Blended Wing-Body Small UAV Designs", Jurnal Teknologi, 5, 103-109 (2015)

[10] Z. M. Ali, W. Kuntjoro, W. Wisnoe, R. E. M. Nasir, F. Mohamad, and N. F. Reduan, N.F., "The aerodynamics performance of Blended Wing Body Baseline-II E2", IEEE 3rd International Conference on Communication Software and Networks (ICCSN) 2011, 293-297 (2011)

[11] R. E. M. Nasir, N. S. C. Mazlan, Z. M. Ali, W. Wisnoe, and W. Kuntjoro, "A Blended Wing Body Airplane with a Close-Coupled, Tilting Tail”, IOP Conference Series: Materials Science and Engineering, 152 (1) (2016)

[12] W. Wisnoe, R. E. Mohd Nasir, R. Ramly, W. Kuntjoro, and F. Mohamad, "Aerodynamic of UiTM's Blended-Wing-Body Unmanned Aerial Vehicle Baseline-II Equipped with One Central Vertical Rudder", Jurnal Teknologi, 75 (8), 95-99 (2015)

[13] W. Wisnoe, R. E. M Nasir, W. A. Musyamel Saarani, N. Mohd Saad, and M. A. A. Mamud, "Wind Tunnel Tests of UiTM Blended Wing BodyUnmanned Aerial Vehicle (BWB-UAV) Prototype", Journal of Mechanical Engineering, SI 4 (3), 234245 (2017)

[14] M. A. Mohamad Sanusi, "Study on Pitching Behaviour of UiTM's BWB UAV Prototype", Final Year Project Report, Bachelor of Engineering (Hons) (Mechanical), Universiti Teknologi MARA Malaysia (2015) 